Volume No. 1, Issue No. 4 (October-December), pp. 20-28

\title{
Solution of Software Requirement Issues in Software Organizations
}

\author{
Taimoor Hassan, Sara Shahid, Sahira Ahmad
}

\begin{abstract}
A framework is shown in this paper to discuss the issue and solution of software requirements in a software organization. This problem is solved by using a specific framework that based on different steps. Solve the issues of software requirement with the help of this step process and finally, we have a result that is purified from issues. The process is defined as set the purpose and goals, gathering the requirements, engineering the requirement, modeling the requirement, validate or verify the overall requirement in requirement phase, requirement documentation, and management of requirement. The given methodology uses a technique that is specially constructed for the solution of software requirement issues in a software organization. The given approach is based on extracting the information from software requirements and solves their different issues. This approach will very helpful in the organizations that face many problems in software requirements.
\end{abstract}

Keywords-Software Requirement, Software Organization, Requirement Engineering, Requirement Management, Requirement Issues

1,2,3 LGU, Lahore, Pakistan 


\section{INTRODUCTION}

The potential of any code is measured by its stretch, responsibility, and reasonability. Needs engineering play an important role in associate in achieving all those qualities [6]. The foremost goal of demand engineering is to realize economical code that is an effectual combination of demand gathering, their study, arrangements, verification\& validation and implementation [7]. Code demand work as an associate in nursing initial purpose for any code project and square measure came as a group of rules that should be followed [8]. Demand engineering guarantees excellent and partial needs through the procedure to outline check and to convey backing or facilitate what the client wants. The most goal of demand Engineering is to satisfy those needs that square measure essential for the customers' wants consistent with the principles and laws. It may be thought of as techniques and capability that a framework should continue [19]. The square measure lots of problems that face by the developers in needs gathering stage. To contend with all of these problems there should be some explicit methodology or set up that demand engineers may take once to finish in needs gathering. Needs engineering seems to be the quality of any project and if demand engineering is solid than the application is going to be profitable.

\section{RELATED WORK}

Andrea De Lucia and Abdallah Qusef describe the agile methodology that is creating a stir in the community of software development [1]. Techniques of agile are the reaction to traditional ways of developing software. In the implementation of traditional methods, work begins with the elicitation and documentation of a "computer" set of requirements, followed by architectural and high-level design, development and inspection. The industry and technology move too fast, requirements change at rates the swamp traditional methods and customers have become increasingly unable to definitively state their needs up front while, at the same time, expecting more from their software. As a result, several consultants have dependently developed method and practices to respond to the certain change they were experiencing.

Haneen Hijazi, Hashemite University, Jordan Shihadeh Alqrainy, Hasan Muaidi, Doctor of Philosophy Thair Khdour, analysis regarding the various kinds of risk think about computer code development life cycle (SDLC) distinctive and understanding these risks could be a preliminary stage for managing risks with success [2]. SDLC could be a structure 
obligatory on the event of a software package, in keeping with this structure the computer code development method involves 5 completely different phases: demand analysis and definition, design, implementation and unit testing, integration and system testing, and also the operation and maintenance section. Within the computer code identification within the method of distinguishing the things that present a threat to the computer code project success.

Ahmad Nauman Ghazi, Kai Petersen, Sri Sai Vijay Raj Reddy, Harini Nekkanti have conducted a survey to elicit their views on problems and improvement strategies [3]. They had identified 24 problems and 65 strategies. Surveys are one of the experimental investigation methods which are used to collect data from a large population. The focus was on questionnaire-based research. The importance of involving multiple researchers in the analysis of survey results was worried.

Kalimullah Khan, P.V.V.Kumar, Azeem Ahmad, Tabassum Riaz, Waheed Anwer, M. Suleman, Omer Ajmal, Tenvir Ali says that the requirements engineering activities act as a backbone of software development[4]. Every year many cases are enrolled against organizations for not fulfilling product requirements properly.
The most part of failure product relies upon, either by missing imperative requirements or catching immaterial requirements.

SDLC contains the phases where software creates from scrap to a developed product. Requirements Development Life cycle (RDLC) contains the phases where requirements get started, raised, refined, forcefully changed, implemented and validated. The procedures to gather requirements vary industry to industry.

Alcides Quispe, Maira Marques, Luis Silvestre, Sergio F. Ochoa, Romain Robbes have been distinguished as a key issue that influences the achievement rate of projects in most software design organizations [5]. The software engineering group has considered the requirements engineering practices of medium and large-sized organizations widely and has prepared a fantastic and reasonable solution.

These authors study about the common rules that are followed by the small and large-scale software development companies. They found some key issues that mainly affect the efficiency of an organization similar to lack of knowledge about gathering the requirements but they didn't provide any solutions to handle these issues. 


\section{METHODOLOGY}

Set Goals and Objectives

Requirement Gathering

Requirement Engineering

Requirement Modeling

Verify \& Validate the Requirement

Document the Requiremen

Requirement Management

Figure 1: Used Approach

\section{a. Set Goals and Objectives}

In this phase, first of all, we set a goal to achieve a relevant result in the shape of solution that is removing the issues of software requirements.

\section{b. Requirement Gathering}

The Requirements gathering procedure will help in understanding the necessities of a client, particularly in the IT business. Several tools and techniques are utilized by the partners and business examiner to encourage this procedure and catch the correct and point by point requirements.

\section{c. Requirement Engineering}

Requirement engineering is the process of determining user expectations for a new or modified product.

\section{d. Requirement Modeling}

It is an structure development arrange within which a model is developed, certified then reviewed as needed till a suitable modeling is refined from that the ultimate application will currently be developed.

\section{e. Verify and Validate the Requirements}

Verification could be a method of the end that the image and established application totally concentrates on documented needs. Validation is that the method of examining the completeness and correctness of needs.

\section{f. Document the Requirement}

In this stage, we are going to review all requirements in the requirement document and then finalized it.

\section{g. Requirement Management}

In this stage, we are going to review all requirements in the requirement document and then finalized it.

\section{RESULTS}

This section discusses a small case study that is time monitoring software system. This section explains the working on case study problem and also shows the output of the process. 


\section{a. Set Goals and Objectives}

The first step is ready Goals and Objective. It's thought-about because of the basic stage of needs gathering method. During this stage, the arrangement is to acknowledge original problems that we would like to resolve.

\section{b. Requirement Gathering}

In the second step of this used framework, requirement gathering from the Time Monitor Software System (TMSS). There are total 27 requirements that is fetch out from Case Study Problem.

\section{c. Requirement Engineering}

The third and major step is to engineering the requirements in a specific and meaningful manner that is very helpful to develop the overall project.

After the irrelevant and incorrect requirements following 16 requirements are cleaned and correct:

\section{Table 1: Cleaned Requirements}

\begin{tabular}{|l|l|}
\hline Requirements & Description \\
\hline R1 & $\begin{array}{l}\text { TMSS permission to } \\
\text { the software makes to } \\
\text { use a www based } \\
\text { browser }\end{array}$ \\
\hline R2 & $\begin{array}{l}\text { In a database store the } \\
\text { timestamp records }\end{array}$ \\
\hline R3 & To analyze the \\
\hline
\end{tabular}

\begin{tabular}{|c|c|}
\hline & $\begin{array}{l}\text { timestamp records that } \\
\text { the permit the manager }\end{array}$ \\
\hline R5 & Unique identification \\
\hline R9 & $\begin{array}{l}\text { The week starts on } \\
\text { Monday based on } \\
\text { current week }\end{array}$ \\
\hline R10 & $\begin{array}{ll}\text { Week ending on } \\
\text { Sunday } & \end{array}$ \\
\hline R11 & $\begin{array}{l}\text { Unit task working is } \\
\text { defined by manager }\end{array}$ \\
\hline R12 & $\begin{array}{l}\text { Developer is } \\
\text { accountable }\end{array}$ \\
\hline R13 & $\begin{array}{l}\text { Use the starting and } \\
\text { ending dates with the } \\
\text { help of schedule }\end{array}$ \\
\hline R15 & $\begin{array}{l}\text { Manager defines the } \\
\text { activities }\end{array}$ \\
\hline R16 & $\begin{array}{l}\text { Select activities that } \\
\text { are representative }\end{array}$ \\
\hline R17 & $\begin{array}{l}\text { Activities done during } \\
\text { record time }\end{array}$ \\
\hline R20 & $\begin{array}{l}\text { Artifacts, activities are } \\
\text { predefined for project }\end{array}$ \\
\hline R21 & $\begin{array}{l}\text { Stored the artifacts \& } \\
\text { etc. in database of } \\
\text { TMT system }\end{array}$ \\
\hline R22 & $\begin{array}{l}\text { User configuration of } \\
\text { system }\end{array}$ \\
\hline R24 & $\begin{array}{l}\text { Username, passwords } \\
\text { available for user }\end{array}$ \\
\hline
\end{tabular}

d. Requirement Modeling 
Based on requirements, we develop a requirement model that is showing different requirements and their relationship with one another. In this stage, we use a domain model that shows in the below diagram, this diagram represents the different relations with one requirement to another requirement. After cleaning the requirements, the remaining essential requirements represent in diagram are given below:

$\mathrm{R}=\left\{\mathrm{R}_{1}\right.$,

$\mathbf{R}_{2}, \mathbf{R}_{3}, \mathbf{R}_{5}, \mathbf{R}_{9,} \mathbf{R}_{10}, \mathbf{R}_{11}, \mathbf{R}_{12}, \mathbf{R}_{13}, \mathbf{R}_{15}, \mathbf{R}_{16}, \mathbf{R}_{17}, \mathbf{R}_{2}$ $\left.{ }_{0}, \mathbf{R}_{21}, \mathbf{R}_{22}, \mathbf{R}_{24}\right\}$

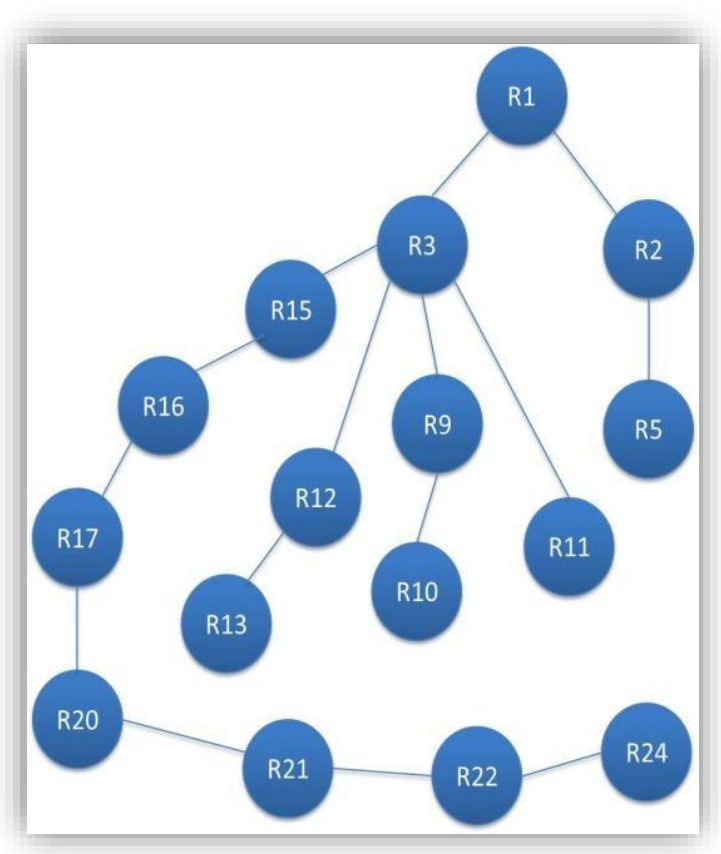

Figure 2: Cleaned Requirement Model

\section{e. Verify and Validate the Requirements}

Verification and Validation are commonly used in the field of software engineering.

There is number of methods that are being used to evaluating the results, but in this scenario, we use the Recall method for evaluate and find out the specific results.

$\mathrm{R}=\frac{\mathrm{N}_{\text {correct }}}{\mathrm{N}_{\text {sample }}}$

In this given formula, $\mathrm{N}_{\text {correct }}$ represent the

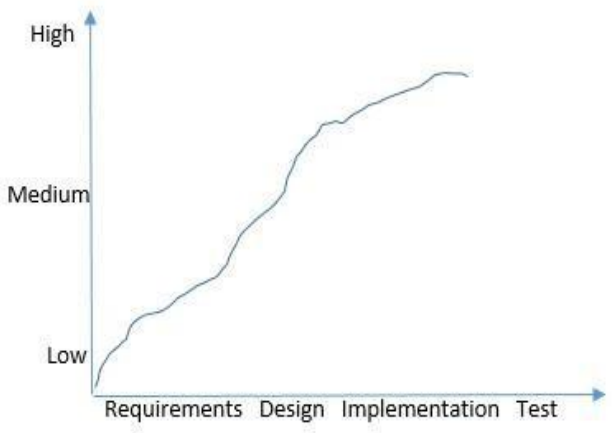

Figure 3: Requirement without validation

accurate requirements and $\mathrm{N}_{\text {sample }}$ represent the complete requirements of software/system.

With the help of this formula, we have total 27 sample requirements but after cleaning and removing unnecessary software requirements we have only 16 
requirements that are correct and other 11 are incorrect. Put the values in above formula:

$\mathrm{R}=16 / 27$

$\mathrm{R}=0.5926$

Validation process plays a great role in the stage of requirements, if we validate, then

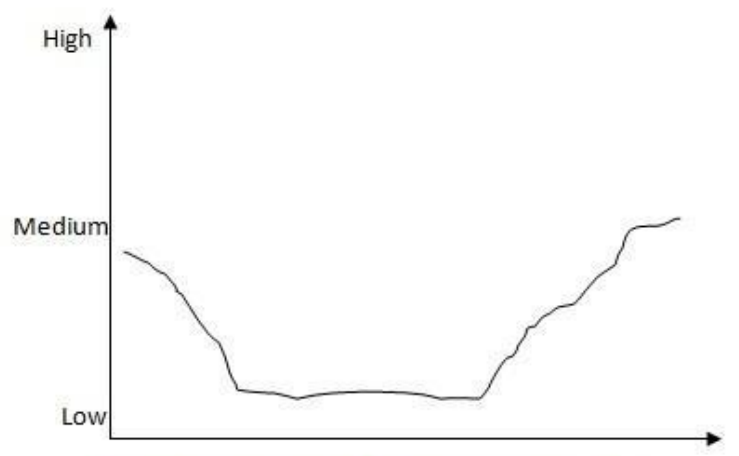

Requirements Design Implementation Test

Figure 4: Requirement with Validation

the chance of errors become very low. The two different ways to represent the validation process during requirements and without the validation process during requirements. The graphs represent the error range from low to high with and without the validation.

In these two graphs, it is shown, if we validate the requirements during requirement phase then the chance of errors becomes low. Another case without validating the requirements the chance of errors becomes high and high.

\section{f. Document the Requirements}

Requirement document is a document which contains all the requirements of a specific product/project/software. In this document defining how the project will perform different functions and techniques in the light of defined instructions.

\section{g. Requirement Management}

As discussed in above chapters, a number of requirements are managing, documentation, collecting, analyzing, capturing, tracing, refining, and prioritizing specific project requirements and then planning for project delivery.

\section{CONCLUSION}

In this paper, associate degree approach was conferred to deal with the matter of software system necessities that exist in numerous software system organizations. This downside is solved by victimization outlined framework to resolve the problem of software system demand. The conferred approach uses a close framework specifically designed for software system demand problems and detailed analysis of software system necessities specifications. The used framework relies on user necessities that involve information 
extracted from existing software system necessities documents and information extracted from completely different parameters. The conferred approach shows that by problems with completely different software system necessities that arise in software system organization and their specific solutions.

\section{PROPOSED FUTURE WORK}

The future of software system requirement is the main focus of this paper. Variety of researchers that's obtainable to the answer of software system demand problems with totally different aspects. Several consultants still operating to explore the vision of software system demand for wellstructured the specification of necessities. With the passage of time, proposed future work is, that mechanically dynamic generation of the need specification with better impact. Embrace their totally different categories, entities, attributes and relationship. That's terribly useful within the modeling of software system necessities and totally different problems with resolution.

\section{ACKNOWLEDGEMENTS}

We would like to thanks my Allah who gave me strength, knowledge, and ability to complete this research paper. Thanks to my supervisor Taimoor Hassan for introducing me to a new topic that is related to software requirements issues and their solution in a different organization. Finally, special thanks to our parents who motivated us with their precious help and support. 


\section{REFERENCES}

[1] De Lucia, A., \& Qusef, A. (2010). Requirements engineering in agile software development. Journal of Emerging Technologies in Web Intelligence, 2(3), 212-220.

[2] Hijazi, H., Alqrainy, S., Muaidi, H., \& Khdour, T. (2014). Risk factors in software development phases. European Scientific Journal, ESJ, 10(3).

[3] Ghazi, A. N., Petersen, K., Reddy, S. S. V. R., \& Nekkanti, H. (2017). Survey research in software engineering: problems and strategies. arXiv preprint arXiv:1704.01090.

[4] Khan, K., Kumar, P. V. V., Ahmad, A., Riaz, T., Anwer, W., Suleman, M., ... \& Chaitanya, A. V. K. (2011, August). Requirement development life cycle: The industry practices. In Software Engineering Research, Management and Applications (SERA), 2011 9th International Conference on (pp. 12-16). IEEE.

[5] Quispe, A., Marques, M., Silvestre, L., Ochoa, S. F., \& Robbes, R. (2010, November). Requirements engineering practices in very small software enterprises: A diagnostic study. In Chilean Computer Science Society (SCCC), 2010 XXIX International Conference of the (pp. 81-87). IEEE.

[6] Ali, W., Rafiq, A., \& Majeed, M. N. (2014). Requirements Engineering in Software Houses of Pakistan. International Journal of Modern Education and Computer Science, 6(9), 47.

[7] Khan, H. H., Mahrin, M. N. R. B., \& Chuprat, S. B. (2013, December). Situational requirement engineering: A systematic literature review protocol. In Open Systems (ICOS), 2013 IEEE Conference on (pp. 123-126). IEEE.

[8] Khan, M. N. A., Khalid, M., \& ul Haq, S. (2013). Review of requirements management issues in software development. International Journal of Modern Education and Computer Science, 5(1), 21. 